\title{
Cost-effectiveness of second-line antihyperglycemic therapy in patients with type 2 diabetes mellitus inadequately controlled on metformin
}

\author{
Scott Klarenbach MD MSc, Chris Cameron BSc MSc, Sumeet Singh BScPharm MSc, Ehud Ur MD
}

\begin{abstract}
Background: Metformin is widely accepted as first-line pharmacotherapy for patients with type 2 diabetes mellitus when glycemic control cannot be achieved by lifestyle interventions alone. However, uncertainty exists regarding the optimal second-line therapy for patients whose diabetes is inadequately controlled by metformin monotherapy. Increased use of newer, more costly agents, along with the rising incidence of type 2 diabetes, carries significant budgetary implications for health care systems. We conducted this analysis to determine the relative costs, benefits and cost-effectiveness of options for second-line treatment of type 2 diabetes.
\end{abstract}

Methods: We used the United Kingdom Prospective Diabetes Study Outcomes Model to forecast diabetes-related complications, quality-adjusted life-years and costs of alternative second-line therapies available in Canada for adults with type 2 diabetes inadequately controlled by metformin. We obtained clinical data from a systematic review and mixed treatment comparison meta-analysis, and we obtained information on costs and utilities from published sources. We performed extensive sensitivity analyses to test the robustness of results to variation in inputs and assumptions.

Results: Sulphonylureas, when added to metformin, were associated with the most favourable cost-effectiveness estimate, with an incremental cost of \$12 757 per qualityadjusted life-year gained, relative to continued metformin monotherapy. Treatment with other agents, including thiazolidinediones and dipeptidyl peptidase-4 inhibitors, had unfavourable cost-effectiveness estimates compared with sulphonylureas. These results were robust to extensive sensitivity analyses.

Interpretation: For most patients with type 2 diabetes that is inadequately controlled with metformin monotherapy, the addition of a sulphonylurea represents the most cost-effective second-line therapy.
$\mathrm{T}$ ype 2 diabetes mellitus is a progressive disease typically treated in a stepwise fashion, beginning with lifestyle modification, followed by the addition of one or more oral antihyperglycemic drugs and, finally, administration of exogenous insulin. Metformin monotherapy is widely recommended as firstline pharmacotherapy, ${ }^{1,2}$ given its favourable effects in controlling blood glucose and body weight, low risk of hypoglycemia, low cost and association with mortality benefit. ${ }^{3}$ Multiple second-line treatment strategies are available for patients in whom glycemic control has become inadequate. These approaches are typically used in addition to continued metformin therapy.,5 Numerous second-line agents are available in Canada, including older oral agents, such as sulphonylureas, and more recently introduced agents, such as thiazolidinediones and dipeptidyl peptidase-4 inhibitors.
The large number of choices for second-line therapy has increased uncertainty regarding the optimal treatment pathway. Recent clinical practice guidelines, including those produced by the Canadian Diabetes Association ${ }^{1}$ and by the American Diabetes Association and the European Association for the Study of Diabetes, ${ }^{2}$ have suggested selecting from among several agents on the basis of their respective advantages and disadvantages. There has been a considerable increase in the use of newer, more costly oral antihyperglycemic agents, which has resulted in substantial increases in associated costs to patients and both public and private drug plans in Canada. ${ }^{4}$ In light of current therapeutic uncertainty, the large proportion of patients requiring second-line therapy over time ${ }^{3,6}$ and the increasing prevalence of type 2 diabetes, ${ }^{7}$ the utilization and cost of second-line therapy are likely to continue to grow.
Competing interests: Scott Klarenbach and Ehud Ur have received honoraria for their participation on the Expert Review Committee of the Canadian Optimal Medication Prescribing and Utilization Service. Ehud Ur has also received honoraria from GlaxoSmithKline, Merck Frosst Canada, AstraZeneca Canada, Novo Nordisk

Canada and Eli Lilly Canada. No competing interests declared by Chris Cameron or Sumeet Singh.

This article has been peer reviewed.

Correspondence to: Sumeet Singh, sumeets@cadth.ca

CMAJ 2011. DOI:10.1503 /cmaj.110178 
Informed decisions regarding optimal prescribing and reimbursement of second-line agents by public and private health care payers requires information about clinical benefits, costs and cost-effectiveness. ${ }^{8}$ As part of a larger initiative to determine optimal prescribing of antihyperglycemic agents, we sought to determine the incremental cost-effectiveness of treatment with alternative second-line agents added to metformin in patients with type 2 diabetes no longer adequately controlled by metformin monotherapy.

\section{Methods}

\section{Description of the model}

We used the United Kingdom Prospective Diabetes Study Outcomes Model $^{9}$ to conduct an incremental cost-utility analysis comparing alternative second-line therapies for adults with type 2 diabetes inadequately controlled by metformin. This validated ${ }^{10}$ model, informed by data from the UK Prospective Diabetes Study, estimates the risk of seven diabetes-related complications and forecasts long-term health and cost outcomes in patients with type 2 diabetes (Figure 1). The model does not incorporate all relevant adverse outcomes. Therefore, submodels were created to account for health and cost consequences (ranging from mild to moderate) for hypoglycemia (ranging from mild to severe) in the reference case, as well as to account for class-specific adverse events in sensitivity analyses. Because glucagon-like peptide-1 analogues were not approved in Canada at the time of our analysis, we did not include this drug class. In the reference case analysis, we assumed that each treatment strategy would continue indefinitely over the patients' lifetimes, without subsequent addition or switching of therapy.

\section{Data sources}

We obtained estimates of clinical effects, including effects on glycosylated hemoglobin, body weight, and overall and severe hypoglycemia, from our recent systematic review and metaanalysis of randomized controlled trials of patients with inadequate control of diabetes with metformin monotherapy. ${ }^{11}$ In that study, we conducted a random-effects mixed treatment comparison meta-analysis by drug class, ${ }^{12}$ in which we compared alternative second-line therapies added to metformin with metformin monotherapy.

The characteristics of simulated patients reflected those in the randomized controlled trials that we included in the previous meta-analysis, when such data were available, or were based on characteristics observed in a Canadian clinical setting. ${ }^{13}$ These patient characteristics were used in the risk equations within the UK Prospective Diabetes Study Outcomes Model over the expected remaining lifetime of a patient with type 2 diabetes. Baseline risks of mild to moderate hypoglycemia were based on the Rosiglitazone Evaluated for Cardiac Outcomes and Regulation of Glycaemia in Diabetes (RECORD) trial, ${ }^{14}$ the longest and largest randomized controlled trial identified in the systematic review, which esti-



Figure 1: Overview of the United Kingdom Prospective Diabetes Study (UKPDS) Outcomes Model and submodels, with application to the current economic analysis. COMPUS = Canadian Optimal Medication Prescribing and Utilization Service, DPP-4 $=$ dipeptidyl peptidase-4, TZDs = thiazolidinediones, QALYs = quality-adjusted life-years. Adapted, with permission, from Clarke and associates. ${ }^{9}$ 
mated a risk of hypoglycemia of $0.86 \%$ per year with metformin monotherapy. The durations of identified trials were too short and their sample sizes too small to capture the rare event of severe hypoglycemia; therefore, we used a large retrospective observational study to estimate this annual risk $(0.05 \%$ in patients using metformin monotherapy). ${ }^{15}$ We performed sensitivity analyses in which we varied the baseline risk of hypoglycemia.

We incorporated quality of life by assigning utility weights for each event in the model (see Appendix 1, available at www.cmaj.ca/lookup /suppl/doi:10.1503/cmaj.110178/-/DC1). As quality of life measures were infrequently and nonuniformly reported in identified trials, we obtained utility weights for long-term diabetes complications in the UK Prospective Diabetes Study model from the community-based EuroQol-5D catalogue (United States) $)^{16,17}$ and EuroQol-5D scores from a study on patients with type 2 diabetes in the United Kingdom ${ }^{18}$ (as previously reported ${ }^{19}$ ). Evidence regarding the effect of hypoglycemia or fear of hypoglycemia on health-related quality of life is limited and of low quality. ${ }^{5,20}$ For the reference case analysis, we assumed that patients experiencing mild to moderate hypoglycemia would have a transient reduction in health-related quality of life. ${ }^{21}$ Episodes of mild to moderate hypoglycemia were assumed to last 15 minutes, ${ }^{22}$ with a disutility of 0.167. . $92,1,23,24$ Severe hypoglycemia was assumed to result in a chronic decrement of 0.01 qualityadjusted life-year or 3.65 quality-adjusted life-days because of fear of future episodes. ${ }^{25}$

\section{Analysis}

We used the perspective of a Canadian thirdparty health care payer ${ }^{26}$ considering only direct costs to the health care system. We obtained annual costs of management of long-term diabetes complications (Appendix 2, available at www.cmaj.ca/lookup/suppl/doi:10.1503/cmaj .110178/-/DC1) from the Ontario Ministry of Health and Long-Term Care, ${ }^{27}$ and we estimated resource use ${ }^{15}$ and costs of severe hypoglycemia ${ }^{28}$ as outlined in a previously published economic evaluation. ${ }^{19}$ We obtained unit costs for drugs from the Ontario Public Drug Programs, when available, ${ }^{29}$ or from other public drug programs in Canada. ${ }^{30-33}$ For the reference case analysis, we used the price of the lowestcost alternative for each drug class (e.g., generic glyburide for sulphonylureas), plus a $10 \%$ markup and $\$ 7.00$ pharmacy fee per 90 -day supply. We assumed maximal doses for metformin ( $2 \mathrm{~g} /$ day), defined daily doses as specified by the World Health Organization for second-line oral agents and observed insulin doses from a patient sample from British Columbia. .11, $19,34^{-1}$

Patients using certain second-line antihyperglycemic drugs (such as insulin secretagogues and insulin) may use more blood glucose test strips, so we derived the average daily utilization of blood glucose test strips for each agent from a recent utilization study in Ontario. ${ }^{35}$ We assumed that patients using non-hypoglycemia-inducing oral glucose-lowering drugs (e.g., metformin, dipeptidyl peptidase-4 inhibitors) would use 0.94 test strips per day, those using sulphonylureas or

Table 1: Daily cost of treatment with and without blood glucose test strips*

\begin{tabular}{|c|c|c|c|c|}
\hline \multirow[b]{2}{*}{ Drug class } & \multirow[b]{2}{*}{ Agent } & \multirow[b]{2}{*}{ Dosage } & \multicolumn{2}{|c|}{ Cost per day, \$† } \\
\hline & & & $\begin{array}{l}\text { Without test } \\
\text { strips }\end{array}$ & $\begin{array}{l}\text { With test } \\
\text { strips }\end{array}$ \\
\hline Metformin & Metformin & $\begin{array}{l}500 \mathrm{mg} \text { four } \\
\text { times daily }\end{array}$ & 0.50 & 1.24 \\
\hline Sulphonylureas & Glyburide & 5 mg twice daily & 0.73 & 1.64 \\
\hline Meglitinides & Repaglinide & 2 mg twice daily & 1.28 & 2.20 \\
\hline Thiazolidinediones & Pioglitazone & 30 mg once daily & 3.00 & 3.74 \\
\hline DPP-4 inhibitors & Sitagliptin & 100 mg once daily & 3.38 & 4.13 \\
\hline $\begin{array}{l}\alpha \text {-Glucosidase } \\
\text { inhibitors }\end{array}$ & Acarbose & $\begin{array}{l}100 \mathrm{mg} \text { three } \\
\text { times daily }\end{array}$ & 1.76 & 2.50 \\
\hline Basal insulin & Insulin NPH & $0.75 \mathrm{U} / \mathrm{kg}$ daily & 1.95 & 3.60 \\
\hline Biphasic insulin & $\begin{array}{l}\text { Regular human insulin or } \\
\text { insulin NPH } 30 / 70\end{array}$ & $1.50 \mathrm{U} / \mathrm{kg}$ daily & 3.81 & 5.45 \\
\hline \multicolumn{5}{|c|}{$\begin{array}{l}\text { Note: DPP- } 4=\text { dipeptidyl peptidase- } 4, \mathrm{NPH}=\text { neutral protamine hagedorn. } \\
\text { *Patients using non-hypoglycemia-inducing oral glucose-lowering drugs were assumed to use } 0.94 \text { strips per day, those using } \\
\text { insulin were assumed to use } 2.08 \text { test strips per day, and those using oral drugs in combination with sulphonylureas or } \\
\text { meglitinides (both of which are associated with hypoglycemia) were assumed to use } 1.16 \text { test strips per day (based on data } \\
\text { from the Ontario Drug Benefit Program). } \\
\text { tFor all agents, costs are for the lowest-cost alternative. }\end{array}$} \\
\hline
\end{tabular}


meglitinides would use 1.16 test strips per day, and those using insulin would use 2.08 test strips per day. We applied a cost of $\$ 0.72$ per test strip, plus a pharmacy fee of $\$ 7.00$ per 100 test strips. We inflated costs to 2009 Canadian dollars using the Health Component of the Canadian Consumer Price Index. ${ }^{36}$ We discounted costs and quality-adjusted life-years at $5 \%$ per annum. ${ }^{26}$ Members of the Expert Review Committee of the Canadian Optimal Medication Prescribing and Utilization Service, which includes four endocrinologists, provided validation of the model inputs.

To examine the robustness of results to changes in parameter and model assumptions over plausible ranges, we conducted one-way and multi-way sensitivity analyses, varying the estimates of clinical effects, price of treatments, dose of treatments, time horizon, discount rates, use of blood glucose test strips, impact of hypoglycemia on health-related quality of life, event rates of hypoglycemia (overall and severe), inclusion of adverse events (e.g., increased risk of congestive heart failure and fractures in patients using thiazolidinediones). We also conducted an analysis in which we assumed that isophane insulin was added when a patient's glycosylated hemoglobin reached 9\% (see Canadian Agency for Drugs and
Technologies in Health ${ }^{37}$ for technical details). We generated cost-effectiveness acceptability curves to illustrate the probability that each second-line therapy was most cost-effective across a range of decision-makers' willingness-to-pay thresholds. ${ }^{8,38,39}$ Net monetary benefit was used to rank strategies using a range of willingness-to-pay thresholds in the reference case, as well as in sensitivity analyses (Appendix 3, available at www.cmaj.ca/lookup /suppl/doi:10.1503/cmaj.110178/-/DC1).

\section{Results}

Sulphonylureas had the lowest daily cost among active second-line treatments, even after the additional cost of blood glucose test strips was applied (Table 1). Compared with metformin, the addition of second-line agents reduced glycosylated hemoglobin by $0.64 \%$ to $0.97 \%$ (Appendix 4, available at www.cmaj.ca/lookup /suppl/doi:10.1503/cmaj.110178/-/DC1). The clinical benefits observed in our systematic review translated into small differences (absolute $-0.2 \%$ to $1.1 \%$ ) in 40 -year cumulative incidence rates between second-line agents plus metformin versus metformin monotherapy (Appendix 5, available at www.cmaj.ca/lookup /suppl/doi:10.1503/cmaj.110178/-/DC1) for out-

Table 2: Cost-effectiveness estimates for second-line therapies

\begin{tabular}{|c|c|c|c|c|c|}
\hline Treatment & $\begin{array}{l}\text { Average cost } \\
\text { over lifetime, } \$\end{array}$ & $\begin{array}{c}\text { Average QALYs } \\
\text { over lifetime }\end{array}$ & $\begin{array}{l}\text { Incremental cost, } \\
\text { relative to metformin, \$ }\end{array}$ & $\begin{array}{l}\text { Incremental QALYs, } \\
\text { relative to metformin }\end{array}$ & $\begin{array}{l}\text { Incremental cost- } \\
\text { effectiveness ratio* }\end{array}$ \\
\hline Metformin & 39924 & 8.72 & NA & NA & NA \\
\hline $\begin{array}{l}\text { Metformin plus } \\
\text { sulphonylurea }\end{array}$ & 40669 & 8.78 & 745 & 0.0583 & $\begin{array}{l}\$ 12757 \text { per QALY } \\
\text { (relative to metformin) }\end{array}$ \\
\hline $\begin{array}{l}\text { Metformin plus } \\
\text { meglitinide }\end{array}$ & 42269 & 8.77 & 2345 & 0.0488 & $\begin{array}{l}\text { Meglitinides dominated } \\
\text { by sulphonylureas }\end{array}$ \\
\hline $\begin{array}{l}\text { Metformin plus } \alpha- \\
\text { glucosidase inhibitor }\end{array}$ & 42797 & 8.78 & 2873 & 0.0606 & $\begin{array}{l}\text { \$939 } 479 \text { per QALY } \\
\text { (relative to } \\
\text { sulphonylureas) }\end{array}$ \\
\hline Metformin plus TZD & 46202 & 8.78 & 6278 & 0.0613 & $\begin{array}{l}\$ 4621828 \text { per QALY } \\
\text { (relative to } \alpha \text { - } \\
\text { glucosidase inhibitors) }\end{array}$ \\
\hline $\begin{array}{l}\text { Metformin plus } \\
\text { DPP-4 inhibitor }\end{array}$ & 47191 & 8.78 & 7267 & 0.0601 & $\begin{array}{l}\text { DPP-4 inhibitors } \\
\text { dominated by TZDst }\end{array}$ \\
\hline $\begin{array}{l}\text { Metformin plus } \\
\text { basal insulin }\end{array}$ & 47348 & 8.77 & 7424 & 0.0492 & $\begin{array}{l}\text { Basal insulin dominated } \\
\text { by TZDst }\end{array}$ \\
\hline $\begin{array}{l}\text { Metformin plus } \\
\text { biphasic insulin }\end{array}$ & 52367 & 8.78 & 12443 & 0.0567 & $\begin{array}{l}\text { Biphasic insulin } \\
\text { dominated by TZDst }\end{array}$ \\
\hline \multicolumn{6}{|c|}{$\begin{array}{l}\text { Note: DPP- } 4=\text { dipeptidyl peptidase-4, NA = not applicable, QALY = quality-adjusted life-year, TZD = thiazolidinedione. } \\
\text { *Each strategy was compared with a relevant comparator. For example, because meglitinides are more costly but result in fewer QALYs than sulphonylureas, they } \\
\text { are dominated by the sulphonylureas. As such, the next most costly type of agent ( } \alpha \text {-glucosidase inhibitors) was compared with sulphonylureas. Similarly, TZDs } \\
\text { were compared with } \alpha \text {-glucosidase inhibitors, but because DPP-4 inhibitors, basal insulin and biphasic insulin are more costly and lead to fewer QALYs than TZDs, } \\
\text { they are dominated by the TZDs (which are less expensive and more effective). } \\
\text { tDPP-4 inhibitors, basal insulin and biphasic insulin are dominated by TZDs only if it is assumed that use of TZDs (e.g., generic pioglitazone) is not associated with } \\
\text { an increased risk of congestive heart failure. However, recent evidence suggests that this assumption is invalid and that use of TZDs is associated with an increased } \\
\text { risk of congestive heart failure. }{ }^{14} \text { If it is assumed that patients using TZDs have an increased risk of congestive heart failure, then use of DDP-4 inhibitors, basal } \\
\text { insulin or biphasic insulin is more cost-effective than TZDs (see Appendix 4, available at www.cmaj.ca/lookup/suppl/doi:10.1503/cmaj.110178/-/DC1). }\end{array}$} \\
\hline
\end{tabular}


comes such as myocardial infarction, stroke, amputation and blindness.

Total lifetime costs and quality-adjusted lifeyears, incremental costs and quality-adjusted life-years relative to metformin monotherapy, and incremental cost-effectiveness results from the reference case analysis are presented in Table 2. Among active treatments, the addition of a sulphonylurea was associated with the lowest total lifetime costs (\$40 669), whereas addition of biphasic insulin incurred the highest lifetime costs (\$52 367). There were small differences in quality-adjusted life-years gained between metformin monotherapy and addition to metformin of second-line treatment strategies (0.05 to 0.06$)$, and differences in incremental quality-adjusted life-years were smaller still between the second-line options $(\leq 0.0125)$. As such, cost-effectiveness estimates were largely driven by the difference in prices across treatments. Treatment with a sulphonylurea and metformin was associated with the most favourable cost-effectiveness estimate, with an incremental cost of \$12 757 per qualityadjusted life-year gained relative to metformin monotherapy. Other active treatments were associated with relatively unfavourable costeffectiveness estimates when compared with the next least costly treatment.

The cost-effectiveness acceptability curves (Figure 2) showed that sulphonylurea with metformin had the highest probability of being the most cost-effective strategy beyond willingnessto-pay thresholds of about $\$ 12000$ per qualityadjusted life-year. These results were robust to changes in estimates of clinical effect, price of treatments, dose of treatments, time horizon, discount rates, use of blood glucose test strips, impact of hypoglycemia on health-related quality of life, event rates of hypoglycemia (overall and severe), inclusion of adverse events (increased risk of congestive heart failure and fractures in patients using thiazolidinediones $)^{14}$ and alternative scenarios of resource use and the impact of diabetes-related complications on health-related quality of life (Appendix 6, available at www.cmaj.ca/lookup/suppl/doi:10.1503 /cmaj.110178/-/DC1). Sulphonylureas remained attractive under a scenario where add-on insulin therapy was initiated for all second-line agents once glycosylated hemoglobin rose above $9 \%$, and where greater quality-of-life decrements were assumed for weight gain and for both mild to moderate and severe hypoglycemia. In all instances, sulphonylureas were the most costeffective strategy if decision-makers were willing to pay $\$ 50000$ per quality-adjusted lifeyear gained.

\section{Interpretation}

Our cost-effectiveness analysis, conducted with a validated model of type 2 diabetes and informed by a recent mixed treatment comparison meta-analysis and Canadian cost data, indicated that the addition of a sulphonylurea would be the most cost-effective second-line therapy in patients with type 2 diabetes inadequately controlled by metformin monotherapy. This conclusion was unaltered in sensitivity analyses, where model inputs were varied over their plausible ranges, and over a relevant range of willingness-to-pay thresholds. Since the initial preparation of this report, the prices of sulphonylureas have been halved in some provinces, which would further improve the cost-effectiveness of this class.

Our finding that second-line agents led to a modest reduction in glycosylated hemoglobin, similar to that achieved with metformin monotherapy, is consistent with other systematic reviews. ${ }^{40}$ Where there were slight differences between treatments, they translated into only very minor differences in long-term complications. With similar glycemic control, secondline agents with greater treatment costs would require additional clinical benefits for them to be considered cost-effective. Relative differences in the risk of hypoglycemia favoured thiazolidinediones, dipeptidyl peptidase-4 inhibitors

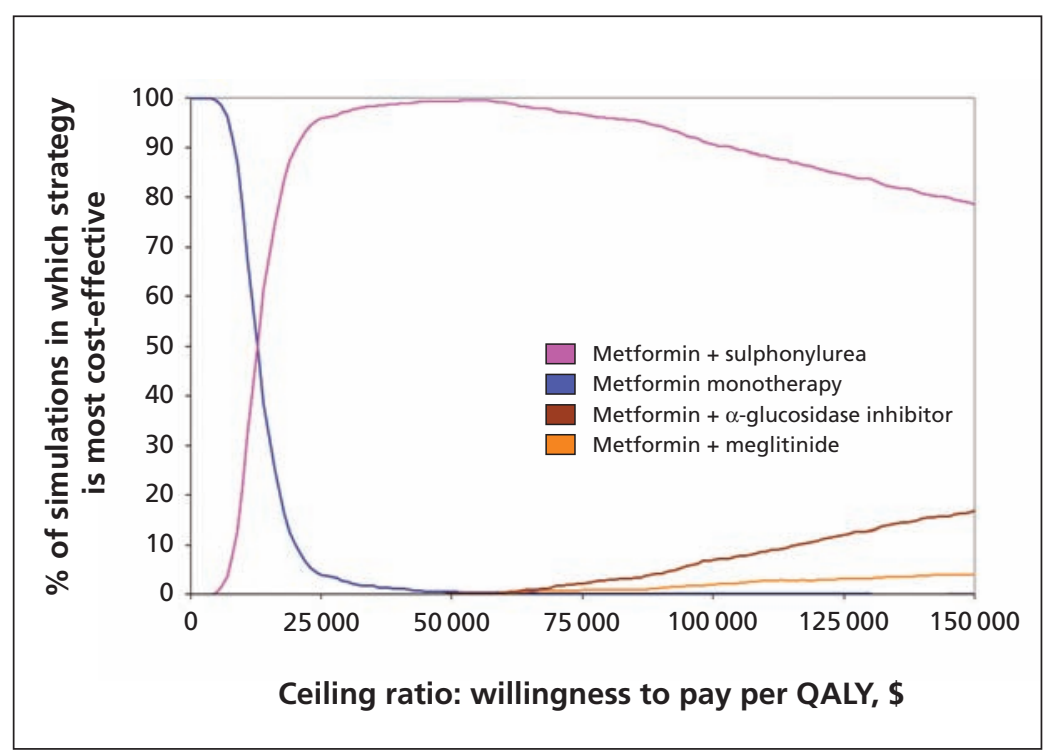

Figure 2: Cost-effectiveness acceptability curves for reference case analysis. These curves show the probability that second-line therapies are cost-effective across a range of decision-makers' willingness-to-pay thresholds, using probabilistic sensitivity analysis. For example, at a willingness-to-pay of $\$ 25000$ per quality-adjusted life-year (QALY), metformin with a sulphonylurea is more likely to be cost-effective than metformin monotherapy (96\% v. $4 \%)$. Some strategies (e.g., thiazolidinediones) are not visible, either because they have low probability of being most cost-effective or because they would only be acceptable at very large willingness-to-pay thresholds. 
and $\alpha$-glucosidase inhibitors, but this did not make these drug classes more cost-effective than sulphonylureas, even when large decrements in quality of life were assigned to hypoglycemia. This relatively minor effect was partly due to the low absolute risk of severe hypoglycemia associated with sulphonylureas, ${ }^{14,15}$ which resulted in small differences in absolute risk. Similarly, although differences in weight change were noted, they were typically less than 3 to $4 \mathrm{~kg}$ and did not have a substantial effect on model results, even when a disutility associated with weight gain was incorporated..$^{41,42}$ We attempted to use our model to accurately capture the effect of all relevant health outcomes, but uncertainty exists regarding the disutility associated with insulin use, ${ }^{43-45}$ weight gain ${ }^{41,42}$ and hypoglycemia. ${ }^{20}$ Sensitivity analyses over plausible ranges did not alter results in the base case, but further research is needed to better define the impact of insulin use, weight gain and hypoglycemia on quality of life.

As expected, inclusion of other adverse events in the model, such as congestive heart failure for thiazolidinediones, made certain agents less attractive. Unlike sulphonylureas, which have an established safety profile because of their longevity on the market, greater uncertainty exists regarding the long-term safety of newer drugs. For example, the safety profile of dipeptidyl peptidase-4 inhibitors is still emerging, because they were introduced relatively recently. If future trials demonstrate clinical benefit or adverse outcomes with newer antihyperglycemic agents, their cost-effectiveness ratios may be altered.

\section{Limitations}

First, our assumption that patients stay on the same therapy indefinitely does not reflect the progressive nature of the disease or clinical practice. However, sensitivity analyses in which failure of second-line treatment (glycosylated hemoglobin $\geq 9 \%$ ) would eventually result in addition of insulin did not fundamentally alter our conclusions. Second, estimates of clinical benefit were limited by generally poor methodologic quality, short duration of studies and use of the surrogate of glycosylated hemoglobin. ${ }^{11}$ Although these limitations are considerable, the burden of proof lies with newer, more costly agents to demonstrate clinically relevant benefits relative to standard care in future randomized controlled trials.

Gradual loss of glycemic control is observed in patients with type 2 diabetes, ${ }^{6}$ and there is speculation that newer agents such as the incretins (i.e., dipeptidyl peptidase-4 inhibitors and glucagon-like peptide-1 analogues) may prolong glycemic control by slowing the decline of $\beta$-cell function and could thereby delay the initiation of insulin. However, the evidence supporting this proposed benefit is limited. ${ }^{46}$ In fact, a recent randomized controlled trial ${ }^{46}$ suggested that dipeptidyl peptidase-4 inhibitors do not confer benefits in terms of sustained glycemic control. Nevertheless, if future long-term studies demonstrate differences in glycemic durability between agents over time, or in other clinically important outcomes, cost-effectiveness estimates will have to be updated.

The results of this cost effectiveness analysis are generalizable to patients with type 2 diabetes in Canada. However, analogous conclusions are likely to be reached in other countries with similar price gradients among second-line agents. Indeed, other independent groups such as the National Institute for Health and Clinical Excellence have reported similar findings. ${ }^{47}$

\section{Conclusion}

In our model, we found that the addition of a sulphonylurea to metformin was associated with the most favourable cost-effectiveness results. This finding was primarily driven by the low cost of sulphonylureas relative to other drugs, marginal differences in glycemic control and longterm complications between sulphonylureas and other agents, and the low absolute risk of severe hypoglycemic episodes requiring health care resource use. Given the increasing prevalence of type 2 diabetes, the optimal use of antihyperglycemic therapies is of paramount importance. Although individualization of therapy is required for all patients, the addition of a sulphonylurea to metformin has similar efficacy to the addition of other antihyperglycemic drugs and represents the most cost-effective use of health care resources. Widespread use of newer, more expensive oral antihyperglycemic drugs or insulin as secondline therapy in patients with type 2 diabetes would lead to significant increases in drug expenditure without necessarily resulting in significant improvements in patient health. These funds would be better used in providing more cost-effective interventions for the treatment of type 2 diabetes.

\section{References}

1. Canadian Diabetes Association. Canadian Diabetes Association 2008 clinical practice guidelines for the prevention and management of diabetes in Canada. Can J Diabetes 2008;32 Suppl 1: i-S201. Available: www.diabetes.ca/files/cpg2008/cpg-2008.pdf (accessed 2011 July 4).

2. Nathan DM, Buse JB, Davidson MB, et al. Medical management of hyperglycaemia in type 2 diabetes mellitus: a consensus algorithm for the initiation and adjustment of therapy: a consensus 
statement from the American Diabetes Association and the European Association for the Study of Diabetes. Diabetologia 2009; 52:17-30.

3. UK Prospective Diabetes Study Group. UK Prospective Diabetes Study 16. Overview of 6 years' therapy of type II diabetes: a progressive disease. Diabetes 1995;44:1249-58.

4. Current utilization of second-and third-line therapies in patients with type 2 diabetes. CADTH Optimal Therapy Report 4(3). Ottawa (ON): Canadian Agency for Drugs and Technologies in Health; 2010. Available: www.cadth.ca/media/pdf/C1110-CU -Report-2nd-3rd-Line-Agents-final-e.pdf (accessed 2011 July 4).

5. Quick reference guide. Type 2 diabetes: the management of type 2 diabetes. London (UK): National Institute for Health and Clinical Excellence; 2009 [updated 2010]. Available: www.nice .org.uk/nicemedia/pdf/CG87QuickRefGuide.pdf (accessed 2011 July 4).

6. Turner RC, Cull CA, Frighi V, et al.; UK Prospective Diabetes Study (UKPDS) Group. Glycemic control with diet, sulfonylurea, metformin, or insulin in patients with type 2 diabetes mellitus: progressive requirement for multiple therapies (UKPDS 49). JAMA 1999;281:2005-12.

7. Report from the National Diabetes Surveillance System. Diabetes in Canada, 2009. Ottawa (ON): Public Health Agency of Canada; 2009. Available: www.phac-aspc.gc.ca/publicat/2009/ndssdic -snsddac-09/pdf/report-2009-eng.pdf (accessed 2011 July 4).

8. Laupacis A, Feeny D, Detsky AS, et al. How attractive does a new technology have to be to warrant adoption and utilization? Tentative guidelines for using clinical and economic evaluations. CMAJ 1992;146:473-81.

9. Clarke PM, Gray AM, Briggs A, et al. A model to estimate the lifetime health outcomes of patients with type 2 diabetes: the United Kingdom Prospective Diabetes Study (UKPDS) Outcomes Model (UKPDS no. 68). Diabetologia 2004;47: 1747-59.

10. Mount Hood 4 Modeling Group. Computer modeling of diabetes and its complications: a report on the fourth Mount Hood Challenge Meeting. Diabetes Care 2007;30:1638-46.

11. McIntosh B, Cameron C, Singh SR, et al. Second-line therapy in patients with type 2 diabetes inadequately controlled with metformin monotherapy: a systematic review and mixed-treatment comparison meta-analysis. Open Med 2011;5(1):E35-E48.

12. Mixed treatment comparisons. Bristol (UK): University of Bristol; 2009. Available: www.bris.ac.uk/cobm/research/mpes/mtc .html (accessed 2011 July 4).

13. Harris SB, Ekoe JM, Zdanowicz Y, et al. Glycemic control and morbidity in the Canadian primary care setting (results of the diabetes in Canada evaluation study). Diabetes Res Clin Pract 2005; 70:90-7.

14. Home PD, Pocock SJ, Beck-Nielsen H, et al. Rosiglitazone evaluated for cardiovascular outcomes in oral agent combination therapy for type 2 diabetes (RECORD): a multicentre, randomised, open-label trial. Lancet 2009;373:2125-35.

15. Leese GP, Wang J, Broomhall J, et al. Frequency of severe hypoglycemia requiring emergency treatment in type 1 and type 2 diabetes: a population-based study of health service resource use. Diabetes Care 2003;26:1176-80.

16. Sullivan PW, Ghushchyan V. Preference-based EQ-5D index scores for chronic conditions in the United States. Med Decis Making 2006:26:410-20.

17. Sullivan PW, Lawrence WF, Ghushchyan V. A national catalog of preference-based scores for chronic conditions in the United States. Med Care 2005;43:736-49.

18. Clarke P, Gray A, Holman R. Estimating utility values for health states of type 2 diabetic patients using the EQ-5D (UKPDS 62). Med Decis Making 2002;22:340-9.

19. Cameron C, Coyle D, Ur E, et al. Cost-effectiveness of selfmonitoring of blood glucose in patients with type 2 diabetes mellitus managed without insulin. CMAJ 2010;182:28-34.

20. Currie CJ, Morgan CL, Poole CD, et al. Multivariate models of health-related utility and the fear of hypoglycaemia in people with diabetes. Curr Med Res Opin 2006;22:1523-34.

21. An economic evaluation of insulin analogues for the treatment of patients with type 1 and type 2 diabetes mellitus in Canada. Optimal Therapy Report 2(4). Ottawa (ON): Canadian Agency for Drugs and Technologies in Health; 2008. Available: http://cadth .ca/media/compus/reports/compus_Economic_IA_Report.pdf (accessed 2011 July 4).

22. Ahern J, Tamborlane WV. Steps to reduce the risks of severe hypoglycemia. Diabetes Spectr 1997;10:39-41.

23. Metcalfe S, Evans J, Moodie P. PHARMAC responds on longacting insulin analogues. NZ Med J 2005;118:U1716.

24. Calculating the US population-based EQ-5D index score. Rockville (MD): US Department of Health and Human Services, Agency for Healthcare Research and Quality; 2005. Available:
www.ahrq.gov/rice/EQ5Dscore.htm (accessed 2011 July 4).

25. Centre for Clinical Practice. Type 2 diabetes: newer agents for blood glucose control in type 2 diabetes. NICE short clinical guideline 87. London (UK): National Institute for Health and Clinical Excellence; 2009. Available: www.nice.org.uk/nicemedia /pdf/CG87ShortGuideline.pdf (accessed 2009 Jul 9).

26. Guidelines for the economic evaluation of health technologies: Canada. 3rd ed. Ottawa (ON): Canadian Agency for Drugs and Technologies in Health; 2006. Available: www.cadth.ca/media /pdf/186_EconomicGuidelines_e.pdf (accessed 2011 July 4).

27. Goeree R, Lim ME, Hopkins R, et al. Prevalence, total and excess costs of diabetes and related complications in Ontario, Canada. Can J Diabetes 2009;33:35-45.

28. Health costing in Alberta: 2006 annual report. Edmonton (AB): Alberta Health and Wellness; 2006. Available: www.health .alberta.ca/documents/Case-Cost-Hospital-04-05.pdf (accessed 2011 July 4).

29. Ontario drug benefit formulary/comparative drug index. Toronto $(\mathrm{ON})$ : Ontario Ministry of Health and Long-Term Care; 2009.

30. Interactive drug benefit list. Edmonton (AB): Government of Alberta, Alberta Health and Wellness; 2009.

31. Manitoba drug interchangeability formulary: schedule. 61st ed. Winnipeg (MB): Manitoba Health; 2009.

32. Régie de l'assurance maladie du Québec. List of medications [amended edition, in force from 2009 Aug. 19, amendment no. 2 including correction No. 3, in force from the same date]. Québec (QC): Gouvernement du Québec; 2009. Available: www.prod .ramq.gouv.qc.ca/DPI/PO/Commun/PDF/Liste_Med/Liste_Med /liste_med_mod2_2009_08_19_en.pdf (accessed 2011 July 4).

33. Online formulary. Regina (SK): Government of Saskatchewan, Saskatchewan Ministry of Health, Drug Plan and Extended Benefits Branch; 2009. Available: http://formulary.drugplan .health.gov.sk.ca/ (accessed 2011 July 4).

34. Second-line therapy for patients with diabetes inadequately controlled on metformin: addendum to project protocol - August 14, 2009. Ottawa (ON): Canadian Agency for Drugs and Technologies in Health; 2009. Available from: www.cadth.ca/media /compus/pdf/C1110-Protocol-Addendum-as-posted.pdf (accessed 2011 July 4).

35. Gomes T, Juurlink DN, Shah BR, et al. Blood glucose test strips: options to reduce usage. CMAJ 2010;182:35-8.

36. Consumer price index. Ottawa (ON): Statistics Canada; 2009. Available: www.statcan.gc.ca/pub/62-001-x/62-001-x2009004-eng .pdf (accessed 2011 Sep. 28).

37. Second-line therapy for patients with diabetes inadequately controlled on metformin: a systemtatic review and cost-effectiveness analysis. CADTH Optimal Therapy Report 4(2). Ottawa (ON): Canadian Agency for Drugs and Technologies in Health; 2010. Available: www.cadth.ca/media/pdf/C1110_SR_Report_final e.pdf (accessed 2011 July 4).

38. Rocchi A, Menon D, Verma S, et al. The role of economic evidence in Canadian oncology reimbursement decision-making: to lambda and beyond. Value Health 2008;11:771-83.

39. Clement FM, Harris A, Li JJ, et al. Using effectiveness and cost-effectiveness to make drug coverage decisions: a comparison of Britain, Australia, and Canada. JAMA 2009;302: 1437-43.

40. Phung OJ, Scholle JM, Talwar M, et al. Effect of noninsulin antidiabetic drugs added to metformin therapy on glycemic control, weight gain, and hypoglycemia in type 2 diabetes. JAMA 2010;303:1410-8.

41. National Collaborating Centre for Primary Care. Obesity: the prevention, identification, assessment and management of overweight and obesity in adults and children. NICE clinical guideline 43. London (UK): National Institute for Health and Clinical Excellence; 2006. Available: http://guidance.nice.org.uk/CG43 (accessed 2011 July 4)

42. Macran S. The relationship between body mass index and health-related quality of life. York (UK): University of York, Outcomes Research Group, Centre for Health Economics; 2004. Available: www.york.ac.uk/inst/che/pdf/DP190.pdf (accessed 2011 July 4).

43. Matza LS, Boye KS, Yurgin N, et al. Utilities and disutilities for type 2 diabetes treatment-related attributes. Qual Life Res 2007; 16:1251-65.

44. Maddigan SL, Feeny DH, Majumdar SR, et al. Health Utilities Index mark 3 demonstrated construct validity in a populationbased sample with type 2 diabetes. J Clin Epidemiol 2006; 59:472-7.

45. Hauber AB, Johnson FR, Sauriol L, et al. Risking health to avoid injections: preferences of Canadians with type 2 diabetes. Diabetes Care 2005;28:2243-5.

46. Seck T, Nauck M, Sheng D, et al. Safety and efficacy of treatment with sitagliptin or glipizide in patients with type 2 diabetes inad- 
equately controlled on metformin: a 2-year study. Int J Clin Pract 2010;64:562-76.

47. Waugh N, Cummins E, Royle P, et al. Newer agents for blood glucose control in type 2 diabetes: systematic review and economic evaluation. Health Technol Assess 2010;14:1-248.

Affiliations: From the Department of Medicine (Klarenbach), University of Alberta, Edmonton, Alta.; the Canadian Agency for Drugs and Technologies in Health (Cameron, Singh), Ottawa, Ont.; and the Division of Endocrinology (Ur), St. Paul's Hospital and Vancouver General Hospital, University of British Columbia, Vancouver, BC

Contributors: All of the authors contributed to the conception and design of the study. Chris Cameron conducted the analyses, and all authors assisted in interpretation of results. Scott Klarenbach, with the help of Chris Cameron, Sumeet Singh and Ehud Ur, drafted the manuscript. All of the authors critically reviewed the manuscript for important intellectual content and approved the final version submitted for publication.

Funding: This research was supported through a financial contribution from Health Canada to the Canadian Agency for Drugs and Technologies in Health (CADTH). CADTH (www.cadth.ca) is an independent, not-for-profit agency funded by Canadian federal, provincial and territorial governments to provide credible, impartial advice and evidencebased information about the effectiveness of drugs and other health technologies to Canadian health care decision-makers.

Scott Klarenbach is supported by a Population Health Investigator Award from the Alberta Heritage Foundation for Medical Research/Alberta Innovates Health Solutions, and by a joint initiative between Alberta Health and Wellness and the University of Alberta.

Acknowledgement: The authors thank Jennifer Skuce for her help in organizing references. 